\title{
Age-Related Changes in Muscle Fatigue Resistance in Humans
}

\author{
K. Ming Chan, Asim J. Raja, Fay J. Strohschein, Katherine Lechelt
}

\begin{abstract}
Objective: The goal of this study was to compare the relative contributions from the muscle and the central nervous system to muscle fatigue resistance in aging. Methods: Each subject carried out $90 \mathrm{~s}$ of sustained maximal voluntary isometric contraction (MVC) of the thumb using the thenar and forearm thumb muscles. Contractile capacity of the thenar muscles was assessed through tetanic stimulation of the median nerve. Interpolated doublets delivered during an MVC represented the overall voluntary activation level while transcranial cortical stimulation with an electromagnetic stimulator was used to assess motor output upstream from the corticomotoneuronal pathway. Results: Nine elderly subjects [four females and five males, 70 \pm 9 years old (mean \pm SD)] and 10 younger subjects (five females and five males, $30 \pm 6$ years old) were tested. After the fatiguing exercise, the elderly group's MVC declined by $29 \%$ as opposed to $47 \%$ in the younger group $(\mathrm{p}<0.01)$. The elderly group's greater fatigue resistance was accounted for by increased fatigue resistance at the muscle level as well as in the central nervous system. At least some of the decline in the central motor drive was upstream from the corticomotoneuronal pathway. Conclusion: The higher muscle fatigue resistance in the elderly group was attributable to differences in both the peripheral and central nervous systems.
\end{abstract}

RÉSUMÉ: Changements dans la résistance à la fatigue musculaire associés au vieillissement chez l'humain. Objectif: Le but de cette étude était de comparer les contributions relatives du muscle et du système nerveux central à la résistance à la fatigue associée au vieillissement. Méthodes: Chaque sujet a effectué $90 \mathrm{~s}$ de contractions isométriques volontaires maximum soutenues (CVM) du pouce en utilisant les muscles de l'éminence thénar et de l'avant-bras. La capacité contractile des muscles de l'éminence thénar a été évaluée au moyen d'une stimulation tétanique du nerf médian. Des doublets interpolés délivrés pendant une CVM représentaient le niveau d'activation volontaire général alors que la stimulation corticale transcrânienne par un stimulateur électromagnétique a été utilisé pour évaluer le débit moteur en amont de la voir corticomotoneuronale. Résultats: Neuf sujets âgés \{quatre femmes et cinq hommes, âge moyen $70 \pm 9$ ans (moyenne \pm DS) $\}$ et 10 sujets plus jeunes (cinq femmes et cinq hommes, âge moyen $30 \pm 6$ ans) ont été évalués. Après l'exercice induisant la fatigue, la CVM du groupe âgé a diminué de seulement $29 \%$ comparé à $47 \%$ dans le groupe plus jeune $(\mathrm{p}<0.01)$. La plus grande résistance à la fatigue du groupe âgé s'explique par une augmentation de la résistance à la fatigue au niveau musculaire ainsi que dans le système nerveux central. Au moins une partie du déclin de l'activité motrice centrale était en amont de la voie corticomotoneuronale. Conclusion: La plus grande résistance à la fatigue musculaire dans le groupe âgé était attribuable à des différences tant dans le système nerveux périphérique que dans le système nerveux central.

Can. J. Neurol. Sci. 2000; 27: 220-228

Some age-related changes in the motor system are welldescribed. For example, loss and atrophy of muscle fibers with a relatively greater decrease in the number and size of type II muscle fibers occur with aging. ${ }^{1}$ There is also a progressive decline in the number of motoneurons with subsequent reinnervation and expansion of the innervation territory of the surviving motoneurons. ${ }^{2-6}$ In the central nervous system, the extent of upper motoneuron loss with aging is substantial., ${ }^{7,8}$ Taken together, it should not be surprising that some, or all, of these changes may have an impact on the muscle fatigue resistance in elderly individuals. Although muscle fatigue is of great functional importance in daily activities, data on its changes in aging, compared to strength changes, is relatively sparse. Also, reports on age-related changes in muscle fatigue resistance are conflicting. Findings range from increased fatigue resistance, ${ }^{9,10}$ no change, ${ }^{11}$ to decline. ${ }^{12}$ The lack of agreement may, in part, be due to the different conditions under which muscle fatigue was induced and assessed. In some studies, muscle fatigue was induced by artificial electrical stimulation of the peripheral nerve, thus bypassing the central motor system. ${ }^{10-}$ ${ }^{12}$ In contrast, other studies relied on the voluntary contraction force as a gauge for muscle fatigue, which does not discriminate changes in the central from the peripheral components of the motor system. ${ }^{9}$ Since muscle fatigue can be a result of failure of any component along the motor pathway from volitional effort to the contractile capacity of the muscle, it is imperative that both the central and peripheral components be assessed so that their relative changes can be clearly distinguished and the mechanisms differentiated.

From the Division of Physical Medicine and Rehabilitation (KMC), Division of Neuroscience (KMC, AJR, FJS), Department of Geriatric Medicine (KL), Faculty of Medicine, University of Alberta, Edmonton, Alberta, Canada

RECEIVED JANUARY 10, 2000. ACCEPTED IN FINAL FORM MAY 23, 2000.

Reprint requests to: K. Ming Chan, Division of Neuroscience, 513 Heritage Medical Research Center, University of Alberta, Edmonton, Alberta T6G 2S2, Canada 
Therefore, the goals of this study were: i) to investigate the difference in fatigue resistance of the thenar muscles between younger and older subjects, ii) to assess the extent to which the changes in the muscle, versus iii) changes in the central motor system that are responsible for the force decline in muscle fatigue.

\section{METHODS}

\section{Subjects}

Two groups of subjects were recruited. The younger group was between 20 to 45 years of age and the older group from 60 to 88 years of age. These subjects were all healthy without any history of nerve, cardiovascular, respiratory, or connective tissue diseases. Other exclusion criteria included a history or physical examination findings suggestive of carpal tunnel syndrome, a history of trauma to the head and face with possible metal embedded in those areas.

All subjects were right-handed and only the dominant hand was tested. The subjects were asked not to do any heavy repetitive hand activities within two days prior to the test. A medical history was obtained through a personal interview and a careful neurological examination was carried out by the first author. Their physical activity level was determined using the Occupational and Leisure Physical Activity Scale. ${ }^{13}$ The nature of the experiments and the test procedure was explained to the subjects. The study was approved by the Health Research Ethics Board at the University of Alberta and all subjects gave their informed consent.

All subjects were thoroughly familiarized with the test protocol by performing the test twice. Each test was done at least one week apart. Only results from the second test session were used.

\section{Experimental setup (Figure 1)}

The subject was comfortably seated in front of the force platform with the monitor screen and speakers in view for audiovisual feedback. The right forearm and hand were positioned on a forearm splint open on the ventral surface to allow access to the median nerve at the wrist. The splint was in turn rigidly fixed onto the force platform. The entire hand and forearm, except the thenar eminence and the thumb, were securely fastened to the force platform with Velcro straps.

The methods used for transcranial cortical stimulation and twitch interpolation were similar to those described by Gandevia and his coworkers. ${ }^{14}$

\section{Recording}

The force and electrical signals were recorded on a digital oscilloscope (Axoscope, Axon Instruments) at a sampling rate of $5 \mathrm{kHz}$ for off-line analysis.

Force - the contraction force of the thumb was measured by a harness looped around the base of the thumb with a passive preload maintained at $2 \mathrm{~N}$. The harness was connected to a force transducer mounted on a vertical aluminum plate on top of the force platform. The aluminum plate had a 90-degree circular track that allowed the angle of the force transducer to be precisely adjusted to 45 degrees (half way between full flexion and full abduction) in relation to the palm along the line of contraction.

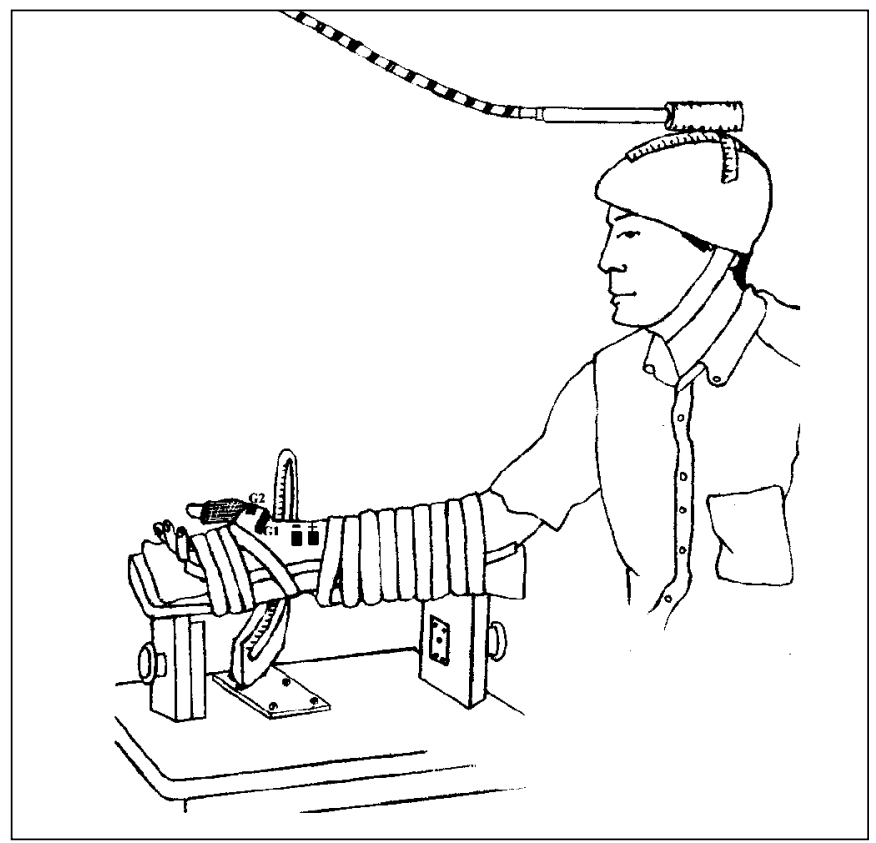

Figure 1: Experimental setup. The bipolar stimulating electrodes were placed over the median nerve at the wrist. (-) denotes the cathode located distally to the anode (+). The recording electrode (G1) was placed over the motor end plate of the median innervated thenar muscles while the reference electrode (G2) was placed over the dorsal aspect of the 1st metacarpophalangeal joint. Details of the rest of the setup are described in the text.

The force transducer (model LCCA-25, Omega Engineering Inc.) output was amplified by using a direct current amplifier (model 842 , Aries Instruments) with a filter bandwidth of $0 \mathrm{~Hz}-1 \mathrm{kHz}$.

Electrical - two self-adhesive disposable surface electrodes (Blue Spot BS3400), each measuring $1 \times 2.5 \mathrm{~cm}$, were used to detect the electromyographic (EMG) signals. The recording electrode was placed directly over the motor point of the median innervated thenar muscles and the reference electrode over the dorsal aspect of the 1st metacarpophalangeal joint. A second set of surface electrodes, with the recording electrode placed over the hypothenar eminence and the reference electrode on the dorsal aspect of the 5th metacarpophalangeal joint, was used to monitor ulnar nerve activation. A large silver-plated disc electrode was placed on the palm to serve as ground. The signal was amplified by an alternating current amplifier (model P511K, Grass Instruments) with a bandwidth of $10 \mathrm{~Hz}-2 \mathrm{kHz}$.

\section{Stimulation}

Peripheral nerve stimulation - the median nerve was stimulated with bipolar stimulating electrodes connected to an electrical stimulator (model S44, Grass Instruments). The stimulating electrodes, each measuring $1.5 \times 0.6 \mathrm{~cm}$ with an inter-electrode distance of $2.5 \mathrm{~cm}$, were securely strapped to the wrist over the median nerve with an elasticized Velcro strap. Stimulus intensity was set at $30 \%$ above the intensity required to maximally stimulate the median nerve $(80-100 \mathrm{~V})$ and the pulse width $0.2-0.6 \mathrm{~ms}$ with the exception of the interpolated doublet. Through pilot studies, we found that during maximum voluntary 


\section{BASELINE}

1. SINGLE PULSE to median nerve, subject at rest

2. DOUBLET to median nerve, subject at rest

3. 8 PULSES at $50 \mathrm{~Hz}$ to median nerve, subject at rest

4. INTERPOLATED DOUBLET to median nerve during brief MVC; immediately followed by DOUBLET to median nerve when subject was relaxed (for normalization)

5. CORTICAL STIMULATION during brief MVC; immediately followed by SINGLE PULSE to median nerve when subject was relaxed (for normalization)

6. Steps 4 and 5 repeated until at least two MVCs with INTERPOLATED DOUBLET and two MVCs with CORTICAL STIMULATION within $10 \%$ of the highest MVC were obtained

\section{FATIGUING EXERCISE}

7. $90 \mathrm{~s}$ MVC, $5 \mathrm{~s}$ rest given after $25 \mathrm{~s}$ and after $55 \mathrm{~s}$

\section{POST FATIGUING EXERCISE TESTS}

8. INTERPOLATED DOUBLET to median nerve just prior to termination of $90 \mathrm{~s}$ exercise

9. DOUBLET to median nerve, subject at rest (for normalization)

10. SINGLE PULSE to median nerve, subject at rest (for normalization)

11. 8 PULSES at $50 \mathrm{~Hz}$ to median nerve, subject at rest 12. CORTICAL STIMULATION during brief MVC

Figure 2: The test protocol. See text for full explanation.

contractions (MVCs), higher intensities were required to maximally stimulate the median nerve because the surface stimulating electrodes were lifted away from the median nerve by the contracting flexor tendons. Therefore, stimulus pulse durations of 2-6 ms were used for the interpolated doublet. At these intensities, the ulnar nerve was also maximally stimulated.

Cortical stimulation - transcranial cortical stimulation was done by using an electromagnetic stimulator (model MES-10, Cadwell Lab). The circular stimulation coil, $9 \mathrm{~cm}$ in diameter, was carefully placed so that the left motor cortex was preferentially activated. After the most optimal location with the lowest stimulation threshold was identified, ${ }^{15}$ the stimulus intensity was set at $50 \%$ above the stimulation threshold. Accurate placement of the magnetic coil was facilitated by fastening it with Velcro straps to a scalp cap lined with distance markers in the sagittal and coronal planes.

\section{Test protocol}

To facilitate the description of the rather complex study protocol, it is summarized in Figure 2 and explained below.

\section{Baseline}

A series of stimuli including a single pulse, a doublet with an interpulse interval of $10 \mathrm{~ms}$ and an 8 pulse train at $50 \mathrm{~Hz}$, each 1s apart, were delivered to the median nerve at the wrist while the subject was at rest (illustrated in Figure 5). The twitch tension was used for measuring the contraction time while the doublet tension was used for comparison with the other baseline resting doublet tensions to ensure reproducibility. Compared with the twitch tension, the tetanic tension is a better representation of the force production capacity of the muscle because it is less influenced by twitch potentiation. This was followed by a series of brief MVCs at a 45 degree angle (half way between full abduction and flexion) from the palm. This angle was chosen because it coincides with the angle of contraction when the median nerve is stimulated at the wrist. The subjects were instructed to contract ballistically and to sustain the maximum force for 3-5 s. During the first brief MVC, an interpolated doublet was delivered to the median nerve once the voluntary contraction had reached a stable plateau. The interpolated twitch technique was first introduced by Merton in the 1950s for measuring the central motor drive and has since been widely used. ${ }^{16-18}$ Because the additional tension produced by an interpolated single pulse stimulus is often very small, its reliability can be enhanced by using a doublet which produces a larger tension that can be more accurately measured and is less susceptible to distortion by an uneven baseline. ${ }^{19}$ This was immediately followed by another doublet after the voluntary contraction had stopped. Cortical stimulation was delivered during the second MVC, immediately followed by a single pulse to the median nerve after the subject had relaxed (illustrated in Figure 7). ${ }^{14}$ This sequence of brief MVCs was repeated with interpolated doublets to the median nerve and cortical stimulation alternately delivered to every other brief MVC. To ensure reproducibility, the subjects were required to produce at least two MVCs with interpolated doublets and two MVCs with cortical stimulation that were within $10 \%$ of the highest MVC. Between four and eight brief MVCs were performed by each subject. The subject was allowed at least two minutes of rest in between each MVC to avoid inducing fatigue.

\section{Exercise}

Each subject was then asked to carry out a sustained MVC for $90 \mathrm{~s}$. A $5 \mathrm{~s}$ rest period was given after $25 \mathrm{~s}$ and again after $55 \mathrm{~s}$. Loud verbal exhortation and audiovisual feedback of their EMG and force output were given to ensure maximal motivation.

\section{Post exercise tests}

Prior to the subject terminating the fatiguing MVC, an interpolated doublet was delivered to the median nerve. This was immediately followed by a series of three stimuli, a doublet, a single pulse and an 8-pulse train at $50 \mathrm{~Hz}$, each $1 \mathrm{~s}$ apart. Within $5 \mathrm{~s}$ of terminating the fatiguing exercise, the subject carried out another brief MVC and a cortical stimulation was applied during the plateau.

\section{Data analysis}

Differences in the weight and height of the two groups of subjects and their physiological parameters were tested using two-tailed independent t-test, with $\mathrm{p}<0.05$ considered statistically significant. 
Table 1. Baseline physiological characteristics of the two age groups.

\begin{tabular}{|c|c|c|c|c|c|c|}
\hline & $\begin{array}{l}\text { Weight } \\
(\mathrm{kg})\end{array}$ & $\begin{array}{l}\text { Height } \\
(\mathrm{cm})\end{array}$ & $\begin{array}{l}\text { MVC } \\
(\mathrm{N})\end{array}$ & $\begin{array}{l}\text { Contraction time } \\
(\mathrm{ms})\end{array}$ & $\begin{array}{l}\text { Tetanic tension } \\
\text { (N) }\end{array}$ & $\begin{array}{l}\text { Voluntary activation } \\
\text { failure index }\end{array}$ \\
\hline $1(\mathrm{~m})$ & 55 & 157 & 72 & 77 & 16.7 & 0 \\
\hline $3(\mathrm{~m})$ & 68 & 173 & 70 & 49 & 29.6 & 0.09 \\
\hline $4(\mathrm{~m})$ & 70 & 178 & 87 & 57 & 26.7 & 0.06 \\
\hline 5 (f) & 59 & 157 & 44 & 63 & 10.0 & 0.46 \\
\hline 8 (f) & 61 & 173 & 80 & 57 & 11.8 & 0.42 \\
\hline $9(\mathrm{~m})$ & 75 & 170 & 106 & 78 & 17.2 & 0.42 \\
\hline $10(\mathrm{f})$ & 64 & 164 & 102 & 71 & 12.5 & 0.10 \\
\hline Older Subjects & $(74.3 \pm 12.6)$ & $(172 \pm 11)$ & $(73 \pm 36)$ & $(80 \pm 17)$ & $(14.4 \pm 8.9)$ & $(0.13 \pm 0.17)$ \\
\hline $15(\mathrm{~m})$ & 93 & 180 & 115 & 78 & 21.5 & 0.04 \\
\hline $16(\mathrm{~m})$ & 95 & 183 & 139 & 81 & 32.4 & 0 \\
\hline 17 (f) & 64 & 152 & 39 & 85 & 4.3 & 0.27 \\
\hline 18 (f) & 75 & 163 & 43 & 74 & 10.2 & 0.16 \\
\hline $19(\mathrm{~m})$ & 77 & 179 & 83 & 55 & 16.2 & 0.05 \\
\hline
\end{tabular}

The mean contraction time was significantly longer in the elderly group $(\mathrm{p}<0.05)$. There was no significant difference in any of the other parameters between the groups. MVC denotes maximal voluntary isometric contraction. (m) denotes male subjects while (f) are the female subjects. The group results are given as $($ mean $\pm \mathrm{SD})$ shown on top of each column. The voluntary activation failure index is defined as interpolated doublet/doublet at rest.

The following physiological parameters were measured and analyzed:

a) Baseline MVC.

b) Baseline tetanic tension (peak tension generated by the 8 pulse train at $50 \mathrm{~Hz}$ ).

c) Contraction time (measured from the twitch tension generated by single pulse stimulus at rest).

d) Baseline voluntary activation failure index defined as: interpolated doublet/doublet at rest. The rationale for using this definition as opposed to the one used by Allen et $\mathrm{al}^{17}$ on the biceps muscle is explained in 'Discussion'.

e) Overall fatigue defined by the decline in MVC from the beginning to the end of the $90 \mathrm{~s}$ exercise.

f) Peripheral fatigue defined by the decline in tetanic tension from baseline to immediately after the $90 \mathrm{~s}$ exercise.

g) Overall central fatigue defined as change in the tension of the interpolated doublet delivered to the median nerve at baseline to that at the end of the $90 \mathrm{~s}$ exercise (illustrated in Figure 6). Because the interpolated doublet tension is affected by the contractile capacity of the thenar muscles, it was normalized to the doublet tension when the muscles were at rest (as shown in Figure 2). Only the baseline interpolated doublet tensions obtained from those brief MVCs within $10 \%$ of the highest MVC were used to calculate the mean baseline value.

h) Change in the capacity to activate the corticomotoneuronal pathway was represented by the tension of the cortically evoked twitch at baseline compared to that immediately following the 90s exercise (illustrated in Figure 7). Because the tension of the cortically evoked twitch is also affected by the contractile capacity of the thenar muscles, it was normalized to the twitch tension of the muscles when the subject was at rest (see Figure 2). Only the baseline cortically evoked twitch tensions obtained from those brief MVCs within $10 \%$ of the highest MVC were used to calculate the mean baseline value.

i) Change in the negative peak amplitude of the maximal compound muscle action potential (CMAP) between baseline and after the fatiguing exercise. (Because the transcranial cortical stimulation was done during an MVC, onset, amplitude and area of the motor evoked potential could not be reliably measured due to the superimposed EMG. Therefore, it was not analyzed).

j) Change in the length of the silent period following cortical stimulation (defined as the duration from the stimulus artifact to the resumption of EMG activity) between baseline and after the fatiguing exercise. ${ }^{14}$

k) Difference in contraction time change following the fatiguing contraction between the two age groups.

Pearson's correlation coefficient was used to compare the subjects' strength and their overall fatigability. 
Table 2: Changes in the physiological parameters following the fatiguing exercise.

\begin{tabular}{lllllll}
\hline & Overall Fatigue & $\begin{array}{l}\text { Tetanic tension } \\
\text { change } \\
(\%)\end{array}$ & $\begin{array}{l}\text { Interpolated } \\
\text { doublet change } \\
\text { (normalized) }\end{array}$ & $\begin{array}{l}\text { Cortical } \\
\text { twitch change } \\
\text { (normalized) }\end{array}$ & $\begin{array}{l}\text { Silent period } \\
\text { change } \\
(\mathrm{ms})\end{array}$ & $\begin{array}{l}\text { CMAP change } \\
\text { np amp } \\
(\mathrm{mV})\end{array}$ \\
Younger group & $47 \pm 10$ & $47 \pm 18$ & $0.92 \pm 0.87$ & $2.25 \pm 2.00$ & $24 \pm 28$ \\
Elderly group & $29 \pm 15^{* *}$ & $22 \pm 27^{*}$ & $0.13 \pm 0.20^{*}$ & $0.20 \pm 2.09^{*}$ & $3 \pm 13$ & $0.09 \pm 1.20$ \\
\end{tabular}

The elderly group exhibited significantly greater muscle fatigue resistance. This was due to a higher peripheral as well as central fatigue resistance. CMAP denotes compound muscle action potential. Overall fatigue is defined as the decline in the MVC force at the end of the $90 \mathrm{~s}$ fatiguing exercise as a percentage of the force at the beginning of the fatiguing exercise. Tetanic tension change represents decline in the tetanic tension of the thenar muscles after the fatiguing exercise as a percentage of the baseline tetanic tension. Changes in the normalized interpolated doublet, normalized cortical twitch and silent period represent the increase in these parameters following the fatiguing exercise.

The numbers represent mean $\pm \mathrm{SD} . *=\mathrm{p}<0.05 ; * *=\mathrm{p}<0.01$. np $=$ negative peak.

\section{RESULTS}

\section{Physical characteristics of the subjects}

Details of the physical attributes of each subject are shown in Table 1 and are summarized here. There were nine elderly [70 \pm 9 years old (mean \pm s.d.)] subjects (four females, five males) and 10 younger ( $30 \pm 6$ years old) subjects (five females, five males). The older subjects were slightly taller $(172 \pm 11 \mathrm{~cm}$ vs. $168 \pm 9 \mathrm{~cm})$ and heavier $(74.3 \pm 12.6 \mathrm{~kg}$ vs. $65.5 \pm 6.2 \mathrm{~kg})$ than the younger subjects but these differences were not statistically significant. All younger subjects were staff and students in the department engaged in sedentary work (group I on the Occupational Activity Scale) while the older subjects were retirees. All subjects in both groups participate in leisure time physical activities at a recreational but not competitive level (group II and III on the Leisure Physical Activity Scale). ${ }^{13}$

\section{Baseline physiological parameters}

Details of these on all subjects are also shown in Table 1. Although not statistically significant, despite being slightly taller and heavier, the elderly group's mean MVC $(73 \pm 36 \mathrm{~N}$ vs. $80 \pm 19$ $\mathrm{N})$ and mean tetanic tension $(14.4 \pm 8.9 \mathrm{~N}$ vs. $16.3 \pm 6.8 \mathrm{~N})$ were lower than the younger age group. In contrast, the mean contraction time was significantly longer $(80 \pm 17 \mathrm{~ms}$ vs. $62 \pm 10 \mathrm{~ms})$ in the elderly group. The mean voluntary activation failure index was slightly lower in the elderly group $(0.13 \pm 0.17$ vs. $0.30 \pm 0.25)$ but this was not statistically significant.

\section{Changes following fatiguing exercise}

The results are summarized in Table 2 and changes in each subject's MVC are shown in Table 3. The elderly group showed greater overall fatigue resistance with a decline of only $29 \%$ in their mean MVC as opposed to $47 \%$ in the younger group

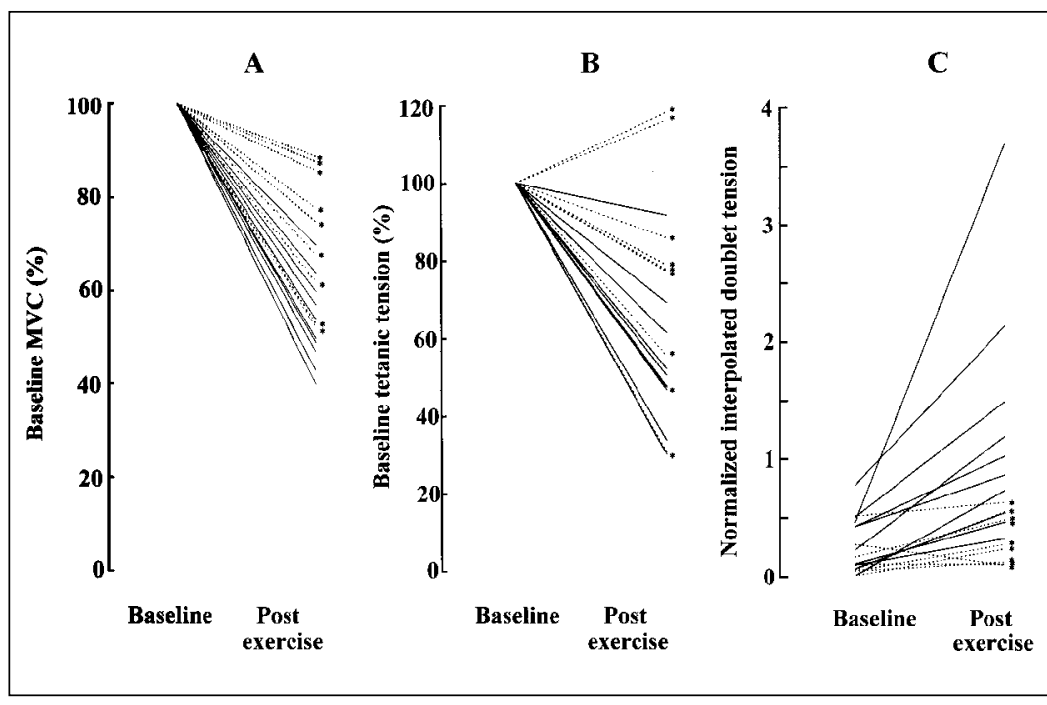

Figure 3: Composite plots for all subjects. (A) Decline in MVC after $90 \mathrm{~s}$ of sustained fatiguing exercise, $(B)$ associated changes in tetanic tension and, $(C)$ normalized interpolated doublet tension. Solid lines represent the younger subjects and dash lines are the older subjects. An asterisk (*) is placed at the end of each dash line to facilitate visual differentiation from the solid lines.

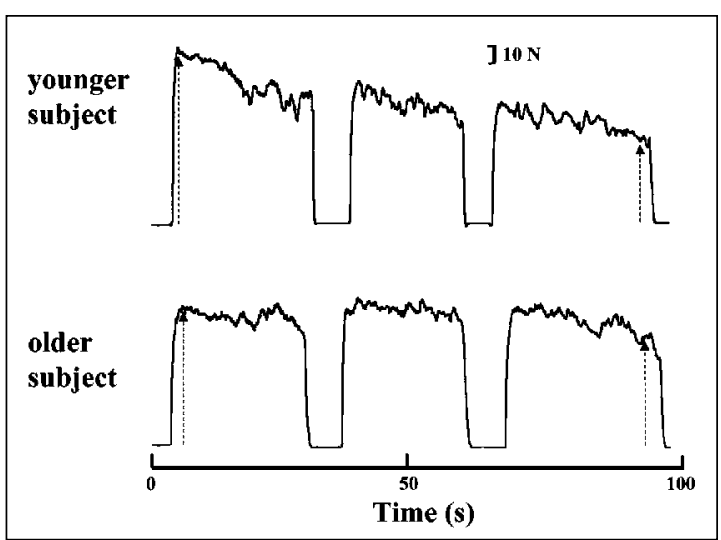

Figure 4: Decline in force during a $90 \mathrm{~s}$ bout of fatiguing exercise. Original force records from a younger (top) and an older subject (bottom). The younger subject's force fell $43 \%$ at the end of the exercise. In contrast, the older subject's force only declined by $25 \%$. The arrows indicate the time points when force measurements were taken. Note that interpolated doublet stimulation was applied to the wrist just prior to termination of the sustained MVC. The force records are displayed in higher gain in Figure 6 to show the interpolated doublet tensions. 


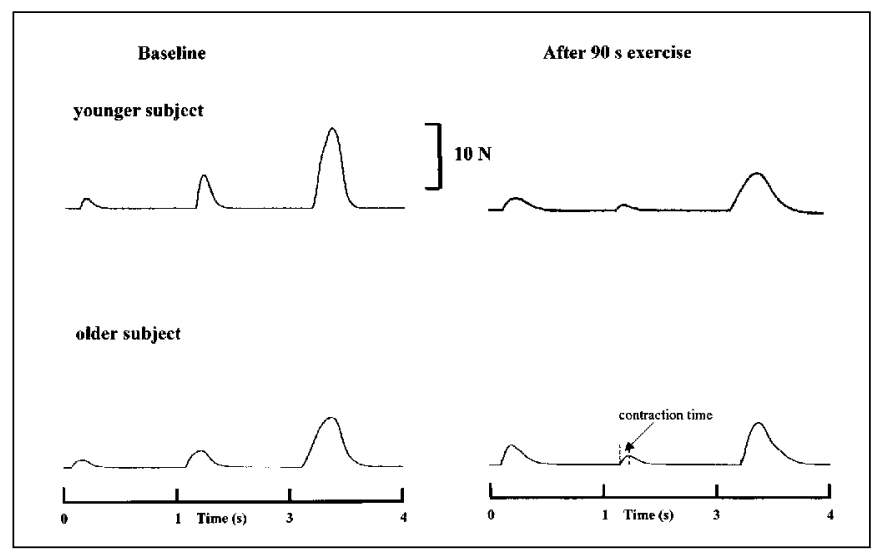

Figure 5: Decline in the muscle contractile capacity following the fatiguing exercise. Original force records showing the twitch, doublet and tetanic tensions from the same subjects as in Figure 3. The younger subject's tetanic tension declined by 52\% after the fatiguing exercise (upper panels) while the tetanic tension in the older subject only declined by $22 \%$ (lower panels). Note that the order of stimulation post exercise was different: doublet, single pulse and, finally, a tetanic train. The two dash lines placed against the single twitch tension at the bottom right force trace illustrate how contraction time was measured from onset to peak.

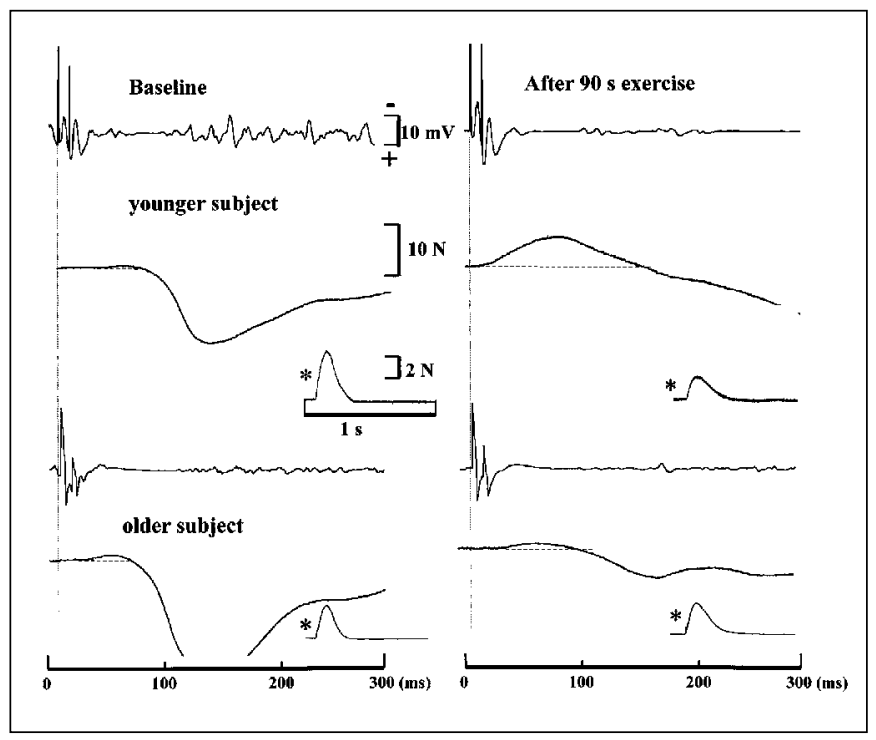

Figure 6: Change in the interpolated doublet tension following the fatiguing exercise. Original electromyographic (top trace) and force (bottom trace) records from the same subjects as in Figure 4. The EMG and force traces are aligned by the stimulus pulse (represented by the vertical dashlines). The doublets at rest (marked with asterisks) used for normalization are shown beneath the interpolated doublet force records. The interpolated doublet tensions are the peak force above the horizontal dashlines. The younger subject's interpolated doublet tension increased markedly following the fatiguing exercise with a change in the normalized tension of 2.35 (upper panel). In contrast, the older subject's normalized tension was unchanged (lower panel). Note that the compound muscle action potentials in the lower panel were distorted by the long duration stimulus artifact.

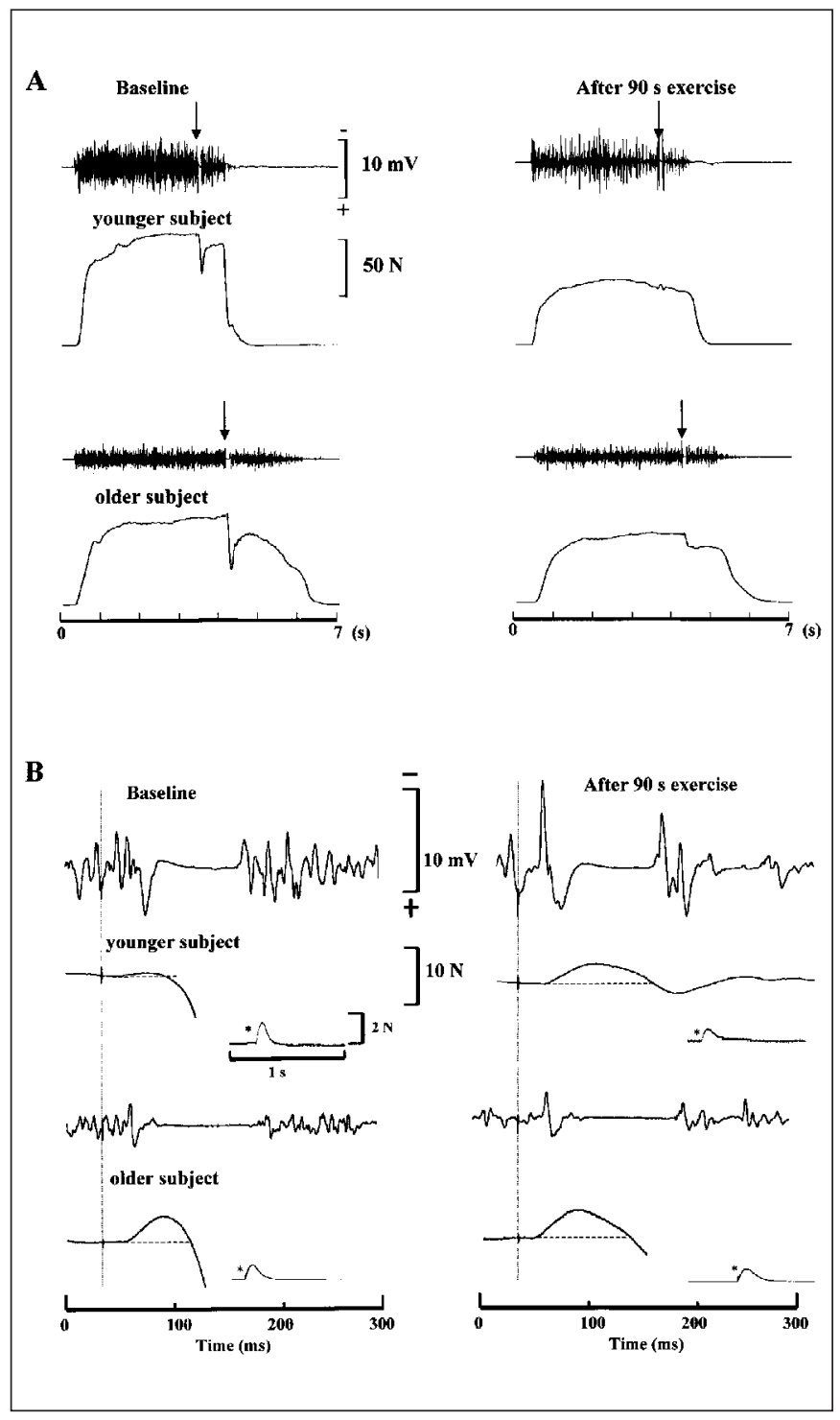

Figure 7: Change in the cortically evoked twitch tension following the fatiguing exercise. A. Original electromyographic (EMG) (top trace) and force (bottom trace) records from the same subjects as in Figure 4. Transcranial cortical stimulation was delivered (as indicated by the arrows) during a brief maximum voluntary contraction (MVC). Following 90 s of fatiguing exercise, the MVC declined by $50 \%$ in the younger subject but by only $23 \%$ in the older subject. The steep fall in $M V C$ immediately after the transcranial stimulation was due to subsequent inhibition resulting in a 'silent period'. B. The EMG and force records displayed at higher gain to show the cortically evoked twitches and motor evoked potentials. The EMG and force traces are aligned by the stimulus pulse (represented by the vertical dashlines). The twitch tensions at rest (marked with asterisks) used for normalization are shown beneath the cortically evoked twitch force records. The cortically evoked twitch tensions are represented by the force peaks above the horizontal dashlines. The younger subject's cortically evoked twitch tension markedly increased following the fatiguing exercise with a change in normalized tension of 4.4 (upper panel). In contrast, the increase in the older subject's normalized cortically evoked twitch tension was only 0.3 (lower panel). 
Table 3: Decline in MVC at the end of the fatiguing contraction.

\begin{tabular}{lccc}
\hline & $\begin{array}{c}\text { Pre-fatigue } \\
\text { (N) }\end{array}$ & $\begin{array}{c}\text { Post-fatigue MVC } \\
(\mathrm{N})\end{array}$ & $\begin{array}{c}\text { Overall fatigue } \\
(\%)\end{array}$ \\
Younger subjects & & \\
1 & 72 & 35 & 51 \\
2 & 86 & 34 & 60 \\
3 & 70 & 30 & 57 \\
4 & 87 & 44 & 50 \\
5 & 44 & 26 & 40 \\
6 & 59 & 41 & 30 \\
7 & 91 & 43 & 53 \\
8 & 80 & 51 & 36 \\
9 & 106 & 57 & 46 \\
10 & 102 & 58 & 43 \\
& & & \\
Older subjects & & & 22 \\
11 & 48 & 37 & 25 \\
12 & 79 & 59 & 14 \\
13 & 71 & 61 & 11 \\
14 & 38 & 34 & 32 \\
15 & 115 & 78 & 38 \\
16 & 139 & 86 & 12 \\
17 & 39 & 34 & 47 \\
18 & 43 & 23 & 48 \\
19 & 83 & 43 & \\
& & & \\
\hline
\end{tabular}

Although there is a general trend of stronger individuals showing a greater degree of overall fatigue, this was not statistically significant (Pearson's $\mathrm{r}=0.39, \mathrm{p}>0.05$ ).

$(\mathrm{p}<0.01)$. The decline in each subject's MVC is shown on the composite plot in Figure 3A. To illustrate their marked differences, original force records from a $90 \mathrm{~s}$ bout of exercise from an elderly subject (subject 12 in Table 1) and a younger subject (subject 10 in Table 1) are showed together in Figure 4. The greater overall fatigue resistance in the elderly group is accounted for by greater peripheral fatigue resistance which is summarized in Figure 3B and illustrated in Figure 5. The mean tetanic tension declined by $22 \%$ in the elderly group as compared to $47 \%$ in the younger group $(\mathrm{p}<0.05)$. Instead of showing a decline, the tetanic tensions in two of nine elderly subjects potentiated following the fatiguing exercise, accounting for the large standard deviation in tetanic tension change in the elderly group. In contrast to the difference in the tetanic tension change between the two age groups, there was no significant change in the mean CMAP negative peak amplitude in either group (an increase of $0.64 \mathrm{mV}$ in the elderly group compared to an increase of $0.09 \mathrm{mV}$ in the younger group) following the fatiguing exercise. A possible reason for this dissociation will be discussed in the next section. The contraction time following the fatiguing contraction became slightly longer in both groups but the between group difference was not statistically significant.

In addition, the elderly also exhibited greater overall central fatigue resistance as reflected by a smaller increase in the normalized interpolated doublet tension $(0.13$ vs. $0.92 ; \mathrm{p}<0.05)$. An example is illustrated in Figure 6 and the magnitude of change in each subject is shown on the composite plot in Figure
3C. At least some of the central fatigue was due to an increased failure to drive the corticomotoneuronal pathway, as the normalized cortically evoked twitch tension also increased (by 0.20 in the elderly group and by 2.25 in the younger group) following the fatiguing exercise. An example is shown in Figure 7. The increase was significantly greater in the younger group $(\mathrm{p}<0.05)$. In line with previous findings, ${ }^{20}$ the silent period lengthened following the fatiguing exercise but the increase was not significantly different between the two age groups.

\section{Discussion}

This is the first study on age-related differences in muscle fatigue resistance that specifically compared the central nervous system contribution with contribution from the muscles. Key findings include: 1) elderly individuals were more fatigue resistant than younger subjects; 2) smaller decline in the central motor drive and the muscle contractile capacity were both responsible for the greater fatigue resistance seen in the elderly, and lastly, 3) failure in the central motor system during fatigue was in part explained by a deficit in the activation of the corticomotoneuronal pathway.

Before attributing the differences in muscle fatigue resistance seen in the two groups to the aging process, three major potential confounding factors have to be considered: differences in physical activity levels, physical stature and gender. In this study, we used a physical activity questionnaire and found no significant difference in the level of physical activity between the two age groups. The lower MVC and tetanic tensions in the elderly subjects also cannot be attributed to their physical stature because they were in fact slightly taller and heavier than their younger counterparts. The greater fatigue resistance in the elderly is also not due to a 'holding back' of voluntary effort as there was no significant difference in the baseline voluntary activation levels between the two groups. Gender differences are also unlikely to be responsible for the observed fatigue resistance difference as the gender composition in both groups is very similar. Besides these major confounding factors, there are likely other variables accounting for the considerable variability among individual subjects as well. With the relatively small sample size in this study, it was not possible to systemically evaluate these variables. They will need to be further investigated in future larger scale studies.

The definition used for quantifying the voluntary activation level in this study is different from that used by Allen et $\mathrm{al}^{17}$ on the biceps muscles. This is because the stimulation methods and the anatomic considerations in the two muscle groups are different. Allen et al directly stimulated the biceps muscles and computed the size of the interpolated twitch as a percentage of the twitch at rest using the equation: [1-(interpolated twitch/control twitch at rest)]x100\%. In the case of the thenar muscles, direct muscle stimulation was not feasible because other intrinsic hand muscles were also co-stimulated to varying degree, thus rendering the force measurements unreliable. In contrast, the median nerve could be easily stimulated at the wrist without co-stimulating the ulnar nerve when the subject was at rest. However, during an MVC, supramaximal stimulation of the median nerve required much higher current density because the contracting flexor tendons at the wrist lifted the skin away from the nerve. At these intensities, it was impossible not to also co- 
stimulate the ulnar nerve. To eliminate any variability due to varying degree of co-activation of the ulnar innervated intrinsic hand muscles, we decided to use a high enough stimulus intensity to also maximally stimulate the ulnar nerve. This intensity level, however, proved to be too uncomfortable when the subjects were at rest. Therefore, the interpolated doublet tension was generated by both median and ulnar innervated intrinsic hand muscles while the doublet tension at rest was only generated by the median innervated muscles. We feel that this approach is justified because this method provided a reliable means to compare the difference in the voluntary activation level between the two age groups which is the main purpose of this study. Since a larger ratio represented a greater voluntary deficit, it was called the voluntary activation failure index.

Although the interpolated twitch technique has traditionally been used for assessing central motor drive deficit, it only provides a global reflection of the central motor drive and does not give any clue on the part of the central nervous system that is responsible for the force decline. ${ }^{16,21,22}$ The additional use of electromagnetic cortical stimulation helps to differentiate the deficit arising from the decline in motor output upstream from the motor cortex from changes in the corticomotoneuronal pathway itself. ${ }^{14}$ However, it must be recognized that the nature of the cortically evoked twitch obtained through electromagnetic stimulation is somewhat different from the peripherally evoked twitch using the interpolated twitch technique. In the cortically evoked twitch, all the thumb flexors, abductors and possibly other hand muscles are activated. In contrast, only the median innervated thenar muscles are stimulated in the case of interpolated doublet at the wrist. Therefore, the magnitude of the two measures cannot be quantitatively compared. Also, the percentage of decline in MVC cannot be directly compared with the percentages of decline in tetanic tension, interpolated doublet and cortically evoked twitch as the muscles activated in each case are not identical. However, these differences should not invalidate the concurrent use of these techniques as it was the relative change within each measure following the fatiguing exercise that is of primary interest. Furthermore, the observed age-related differences in this study could not be attributed to the above technical considerations since the same protocol was applied to both age groups.

An additional caveat is that the results from this study, which employed isometric contraction, may not be generalized to other types of fatiguing muscle contraction as the task-dependent nature of muscle fatigue is well-known. ${ }^{23,24}$ Therefore, studies using other forms of fatiguing exercise may well reveal failure in other components along the motor system pathway (for example, see Bigland-Ritchie et $\mathrm{al}^{25}$ ). This possibility further underscores the importance of assessing the entire central and peripheral systems comprehensively as failure can occur at one or more sites anywhere along the system.

What are the possible physiological mechanisms underlying these observed differences? One possibility is due to changes in muscle fiber composition with age. The proportion and relative diameter of type II muscle fiber have been shown to decline with aging. ${ }^{1}$ The significantly longer contraction time in our elderly group is in keeping with these histologic observations. The greater muscle fatigue resistance in the elderly found in this study might therefore be attributed, in part, to a relative increase in the proportion and size of type I muscle fibers. The lack of change in the size of the CMAP in the face of the decline in tetanic tension following fatiguing exercise suggests that the contractile failure was not a result of action potential propagation failure but, rather, failure at, or distal to, the excitationcontraction coupling mechanism. This suggestion is supported by evidence indicating that in muscle fatigue the safety margin for electrical propagation, at least initially, is increased by an upregulation of the $\mathrm{Na} / \mathrm{K}$ pump activity to minimize the risk of depolarization block. ${ }^{26,27}$

In line with previous studies showing that elderly subjects were equally capable of voluntarily activating the muscles as younger subjects, ${ }^{28,29}$ there was no difference in the voluntary activation level at baseline between the younger and elderly groups in this study. This occurred in spite of evidence of a substantial loss of cortical neurons associated with aging. ${ }^{7,8}$ This apparent discrepancy is somewhat surprising but is in agreement with studies which showed that in patients with amyotrophic lateral sclerosis, a disease in which the number of upper motoneurons is decimated, there was no difference in fatigueinduced changes in central motor drive between the patients and the control group. ${ }^{30}$ If the number of cortical motoneurons is not necessarily the responsible factor, then what are the other possible central sources contributing to muscle fatigue? Given the complexity of the central nervous system, there are likely many factors that collectively contribute to a decline in central motor drive. Potential possibilities include a change in the influence of the peripheral afferent inputs with aging. ${ }^{31,32}$ It is known that muscle afferents do not only project to the spinal cord but also to the brain stem and cortical levels. ${ }^{33,34}$ Sensory signals conveyed from specific peripheral receptors in the limb of primates have been shown to have relatively direct access to the motor cortex.$^{35}$ However, the relative importance of the large diameter myelinated afferents as compared to the smaller type III and IV afferents in muscle fatigue is still controversial. ${ }^{36-40}$ Another group of possible factors are changes in the other cortical and subcortical structures such as the premotor cortex, the supplementary motor area and its subcortical connections.

Although the elderly subjects' muscle fatigue resistance was found to be higher in this study's setting, it does not necessarily infer that muscle fatigue in the elderly is less of a concern in their daily activities. As a result of decreased strength, a larger proportion of their muscle mass would have to be used more frequently in daily tasks which, in turn, may lead to greater muscle fatigue. In considering age-related changes in muscle fatigue resistance, a number of important functional questions have to be addressed. For example, are these age-related changes mutable? Previous studies have clearly shown that strength in the elderly can be improved with training. ${ }^{41,42}$ However, with the commonly known association between the contractile tension and fatigability of muscle fibers, an important question is whether a training program designed to improve strength would necessarily lead to a reduction in muscle fatigue resistance. Given the many possible factors that may have an impact on muscle fatigue resistance, it is difficult to predict the outcome as the muscle contractile properties may not be the most important determining factor.

Another important issue is whether the fatigue resistance of the central nervous system can be separately influenced from the muscle components by different regimes. The answer to this is 
not clear at present. ${ }^{43,44}$ Furthermore, what possible effects such training has on muscle fatigue resistance and what the degree of training specificity is, remain to be demonstrated. Given the vital importance of muscle fatigue resistance in daily activities and the safety of the elderly, a better understanding of its underlying mechanisms and methods of intervention are much needed.

\section{ACKNOWLEDGMENTS}

We thank the Alberta Heritage Foundation for Medical Research for providing salary support to KMC and the Government of Canada for salary support to AJR through a SCP grant. The electromagnetic stimulator was loaned by the Glenrose Rehabilitation Hospital and Capital Health Authority and the other electronic equipment by Dr. William F Brown. The authors also thank Professors Richard S Stein, Aruthur Prochazka and Dr. Robert C Chen for their input to this project.

\section{REFERENCES}

1. Lexell J, Taylor CC, Sjostrom M. What is the cause of the aging atrophy? Total number, size and proportion of different fiber types studied in whole vastus lateralis muscle from 15 to 83 year old men. J Neurol Sci 1988; 84:275-294.

2. Campbell MJ, McComas AJ, Petito F. Physiological changes in ageing muscles. J Neurol Neurosurg Psychiatry 1973; 36:174-182.

3. Doherty TJ, Vandervoort AA, Brown WF. Effects of ageing on the motor unit: a brief review. Can J Appl Physiol 1993; 18:331-358.

4. Doherty TJ, Brown WF. Age-related changes in human thenar motor unit twitch contractile properties. J Appl Physiol 1997; 82:93-101.

5. Doherty TJ, Vandervoort AA, Taylor AW, Brown WF. Effects of motor unit losses on strength in older men and women. J Appl Physiol 1993; 74:868-874.

6. Roos MR, Rice CL, Vandervoort AA. Age-related changes in motor unit function. Muscle Nerve 1997; 20:679-690.

7. Eisen A, Siejka S, Schulzer M, Calne D. Age-dependent decline in motor evoked potential (MEP) amplitude: with a comment on changes in Parkinson's disease. Electroencephalogr Clin Neurophysiol 1991; 81:209-215.

8. Henderson G, Tomlinson BE, Gibson PH. Cell counts in human cerebral cortex in normal adults throughout life using an image analysing computer. J Neurol Sci 1980; 46:113-136.

9. Larsson L, Karlsson J. Isometric and dynamic endurance as a function of age and skeletal muscle characteristics. Acta Physiol Scand 1978; 103:129-36.

10. Narici MV, Bordini M, Cerretelli P. Effect of aging on human adductor pollicis muscle function. J Appl Physiol 1991; 71:1277-1281.

11. Klein C, Cunningham DA, Paterson DH, Taylor AW. Fatigue and recovery contractile properties of young and elderly men. Eur $\mathrm{J}$ Appl Physiol Occup Physiol 1988; 57:684-690.

12. Davies CTM, Thomas DO, White MJ. Mechanical properties of young and elderly human muscle. Acta Med Scand 1986; 711:219-226.

13. Saltin B, Grimby G. Physiological analysis of middle-aged and old former athletes. Comparison with still active athletes of the same ages. Circulation 1968; 38:1104-1115.

14. Gandevia SC, Allen GM, Butler JE, Taylor JL. Supraspinal factors in human muscle fatigue: evidence for suboptimal output from the motor cortex. J Physiol 1996; 490:529-536.

15. Rossini PM, Barker AT, Berardelli A, et al. Noninvasive electrical and magnetic stimulation of the brain, spinal cord and roots: basic principles and procedures for routine clinical application. Report of an IFCN committee. Electroencephalogr Clin Neurophysiol 1994; 91:79-92.

16. Belanger M, McComas AJ. Extent of motor unit activation during effort. J Appl Physiol 1981; 51:1131-1135.

17. Allen GM, Gandevia SC, Mckenzie DK. Reliability of measurements of muscle strength and voluntary activation using twitch interpolation. Muscle Nerve 1995; 18:593-600.

18. Kent-Braun JA, Sharma KR, Weiner MW, Miller RG. Effects of exercise on muscle activation and metabolism in multiple sclerosis. Muscle Nerve 1994; 17:1162-1169.
19. Mckenzie DK, Bigland-Ritchie B, Gorman R, Gandevia SC. Central and peripheral fatigue of human diaphragm and limb muscles assessed by twitch interpolation. J Physiol 1992; 454:643-656.

20. Taylor JL, Butler JE, Allen GM, Gandevia SC. Changes in motor cortical excitability during human muscle fatigue. J Physiol 1996; 490:519-528.

21. Hales JP, Gandevia SC. Assessment of maximal voluntary contraction with twitch interpolation: an instrument to measure twitch responses. J Neurosci Methods 1988; 25:97-102.

22. Merton PA. Voluntary strength and fatigue. J Physiol 1954; 123:553-564.

23. Bigland-Ritchie B, Rice CL, Garland SJ, Walsh ML. Task dependent factors in fatigue of human voluntary contractions. Adv Exp Med Biol 1995; 384:361-380.

24. Enoka RM, Stuart DG. Neurobiology of muscle fatigue. J Appl Physiol 1992; 72:1631-1648.

25. Bigland-Ritchie B, Furbush F, Woods JJ. Fatigue of intermittent submaximal voluntary contractions: central and peripheral factors. J Appl Physiol 1986; 61:421-429.

26. Chan KM, Andres LP, Polykovskaya Y, Brown WF. Dissociation of the electrical and contractile properties in single human motor units during fatigue. Muscle Nerve 1998; 21:1786-1789.

27. Hicks A, McComas AJ. Increased sodium pump activity following repetitive stimulation of rat soleus muscles. J Physiol 1989; 414:337-349.

28. De Serres SJ, Enoka RM. Older adults can maximally activate the biceps brachii muscle by voluntary command. J Appl Physiol 1998; 84:284-291.

29. Vandervoort AA, McComas AJ. Contractile changes in opposing muscles of the human ankle joint with aging. J Appl Physiol 1986; 61:361-367.

30. Sharma KR, Kent-Braun JA, Majumdar S, et al. Physiology of fatigue in amyotrophic lateral sclerosis. Neurology 1995; 45:733-740.

31. Stevens JC. Aging and spatial acuity of touch. J Gerontol 1992; 47:P35-40.

32. Dorfman LJ, Bosley TM. Age-related changes in peripheral and central nerve conduction in man. Neurology 1979; 29:38-44.

33. Brooks VB, Rudomin P, Slayman CL. Sensory activation of neurons in the cats' cerebral cortex. J Neurophysiol 1961; 24:286-301.

34. Phillips CG, Powell TPS, Wiesendanger M. Projections from lowthreshold muscle afferents of hand and forearm to area $3 \mathrm{a}$ of baboon's cortex. J Physiol 1971; 217:419-446.

35. Wolpaw JR. Electromagnetic muscle stretch strongly excites sensorimotor cortex neurons in behaving primates. Science 1979; 203:465-467.

36. Bigland-Ritchie B, Dawson NJ, Johannsson RS. Reflex origin for the slowing of motoneuron firing rates in fatigue of human voluntary contraction. J Physiol 1986; 379:451-459.

37. Gandevia SC, Macefield G, Burke D, Mckenzie DK. Voluntary activation of human motor axons in the absence of muscle afferent feedback. The control of the deafferented hand. Brain $1990 ; 113: 1563-1581$.

38. Garland SJ. Role of small diameter afferents in reflex inhibition during human muscle fatigue. J Physiol 1991; 435:547-558.

39. Garland SJ, McComas AJ. Reflex inhibition of human soleus muscle during fatigue. J Physiol 1990; 429:17-27.

40. Macefield G, Hagbarth KE, Gorman R, Gandevia SC, Burke D. Decline in spindle support to alpha motoneurons during sustained voluntary contractions. J Physiol 1991; 440:497-512.

41. Fiatarone MA, O'Neill EF, Doyle Ryan N, et al. Exercise training and nutritional supplementation for physical fraility in very elderly people. New Eng J Med 1994; 330:1769-1775.

42. Frontera WR, Meredith CN, O'Reilly KP, Knuttgen HG, Evans WJ. Strength conditioning in older men: skeletal muscle hypertrophy and improved function. J Appl Physiol 1988; 64:1038-1044.

43. Herbert RD, Dean C, Gandevia SC. Effects of real and imagined training on voluntary muscle activation during maximal isometric contractions. Acta Physiol Scand 1998; 163:361-368.

44. Yue G, Cole KJ. Strength increases from the motor program: comparison of training with maximal voluntary and imagined muscle contractions. J Neurophysiol 1992; 67:1114-1123. 